\title{
A Time Series Analysis of Satellite Imageries for Land Use \& Land Cover (LULC) Change Detection of Gujranwala City, Pakistan from 1999-2019
}

\author{
Dr. Faiza Mazhar* and Faiza Fadia
}

Government College University Faisalabad, Pakistan; faizamzhr@yahoo.com, faizageo@gmail.com

\begin{abstract}
Objectives: Information on land use and land cover changes are very valuable for the viable expansion of the city. LULC are interrelated attributes in which LC means which type of land is covered with cropland, farmland and grassland and LU means which type of land is used for residential, commercial, Agriculture or Marshland. Methods: This study is an effort to monitor land use/ land cover change by using remote sensing and GIS from 1999 to 2019. The use of remote sensing data has proved to be very helpful in LULC change detection. Accuracy assessment is a vital part of image classification and accuracy assessment is an important technique that defines the quality of the information obtained from the remotely sensed data and is considered an important tool for classification image. Maximum Likelihood supervised classification which was used to create a signature class for land cover. Findings: During the last 20 years our results indicate water, agriculture and mix vegetation decrease $0.1 \%, 7.2 \%$ and $4.1 \%$ but there is more increase in the other two classes barren land increase $2.9 \%$ and built-up increase $7.4 \%$. Mostly agriculture land has been converted into barren and urban land. For the accuracy assessment, overall accuracy assessment was performed. Accuracy assessment was calculated through the Kappa co-efficient index. Applications: For calculating accuracy, we use accuracy statistics, overall accuracy. Temporal changes are time to time changes, in this perspective the change/increase in built-up land is $174.71 \mathrm{sq} \mathrm{km}$. The results of this study would be helpful for decision making, urban development and future planning.
\end{abstract}

Keywords: Land Use, Land Cover, Change Detection, Accuracy Assessment, Temporal

\section{Introduction}

The reservations about land use and land cover changes (LULCC) are accepted on international level. Major causes of land use land cover changes are population growth, urbanization and economic progress have noticeably altered the Earth's surface developments, which causes modifications in ecological characteristics at a regional and global level. ${ }^{1}$ Land-use/cover change literature demonstrates that the dynamics of land use as a consequence of urban expansion shows variability over time and across space. $\underline{2}$ Some regions experience urban growth, while others are characterized by the biggest losses of population. $\underline{3}$ Therefore, regional and local studies focusing on land-use change spatial configuration and pattern driving forces and consequences of land-use change ${ }^{4}$ are increasingly needed in the LULC literature.

Remotely sensing has been commonly known as important data sources for thorough mapping and quantification of land cover changes..$\underline{5}$ Rapid urbanization is likely to persist internationally, but maximum in developing nations. Classifications of Land use/land cover (LULC) are generated to assess the configuration of urban sites and visualize the various segments of the place. Natural and built objects covering the land surface are called "Land cover", while human uses of the land

${ }^{*}$ Author for correspondence 
are called "land use". LULC change detection study has grabbed great attention since the 1970s.. Appropriate and exact LULC change recognition of provides the base for understanding relationships between human and nature. ${ }^{\text {? }}$ Due to rapid urbanization, anthropogenic socioeconomic, administrative and other dynamic powers are playing an important role in LULC change. $\underline{8}$

Transformation of land use and land cover (LULC) is attaining recognition as the main driver of climate change. Urban Expansion has a substantial effect on the environmental mechanism and is a basic element in world climate change. 9 Urbanization is a reaction to the global population increase and its concerns include the conversion of the natural land cover into built-up areas population growth will mostly take place in the city areas and most of the clear surge will be in the municipalities of developing nations. Societal changes in urban areas have caused a change and risk to the landscape's ecology and natural range, $\underline{10}$ and are the reason for modifications in the natural and ecological mechanisms. Temporal spatial data by Remote Sensing (RS) systems help as an incredible base to investigate and measure the modifications over different time in an urban area and supplementary land cover categories. $\underline{11}$

\subsection{Study Area}

Gujranwala is the $7^{\text {th }}$ largest city of Pakistan and $5^{\text {th }}$ most populous city of Punjab. Gujranwala is the well-known populated city of Pakistan. After Karachi and Faisalabad, now Gujranwala is the third-largest industrial center in Punjab and contributes 5 percent in Pakistan National GDP. Population density is higher in many other cities of Punjab and there increase many problems in urban facilities like Gujranwala which is a popular city in Punjab. Gujranwala is located between latitude in east and 74 longitude in the north, on the east side daska, west side Nowshehra Vikran, Northside Kamoke and south side Waziraadab. Figure 1 is showing the location of Gujranwala city.

This study is essential for measuring land use and land cover changes in Gujranwala. The changes that have occurred in the LULC pattern due to spatial expansion of urban areas are significant for land management. This study will provide a better understanding of land utilization. For accurate development, it is important to monitor the going process of the LULC pattern among the previous years. The current study will focus on the urban expansion and development of urban areas in Gujranwala.

This is very important to evaluate the spatial pattern and type of LULC changing to project future development. Planners and resource managers need a reliable technique to asses these consequences by monitoring, detect process and analyzing LULC changing.

Due to this research, any researcher quantify the pattern of LULC change of the past years of Gujranwala city that contain valuable resources for urban decisionmakers and planners to provide accurate land use and environment-related planning. $\underline{12}$
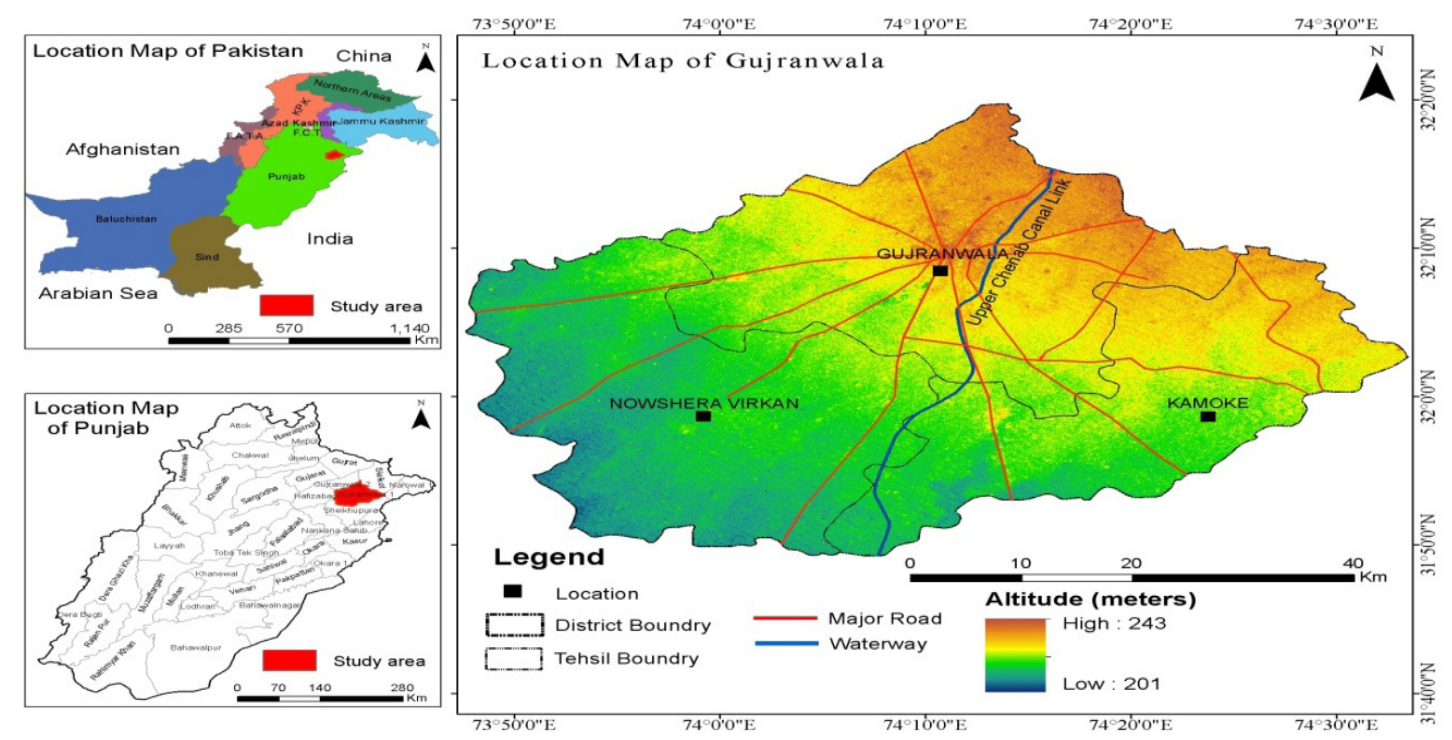

Figure 1. Location of the study area. Source (Author 2019) 


\section{Materials and Methods}

Our research study area is Gujranwala which is the biggest district of Pakistan. For measuring the temporal growth of change detection satellite data was downloaded from the USGS website and Google Earth. Secondary sources are urban unit Municipal Authority, Government development Authority and other linking sources like Historical maps and published reports. From the USGS website, 5 temporal satellite images were selected. The supervised classification technique was adopted for image classification from 1999 to 2019.

Table 1 describes that we get five images of different land sat from the USGS website with resolution $30 \mathrm{~m}$ for showing different time periods of land use and land cover changes. The land sat 5 TM image for 1999 image classification, Land sat 7 ETM image for 2004 image classification, Land sat 8 ETM image for 2009, 2014 and 2019. We use the multispectral band for 5 images.

\subsection{Image Classification}

For our study, we do supervise classification and use the most common type of supervised classification which is maximum livelihood supervised classification. For this classification, we selected areas on the basis of information. For the presentation of land use land cover classes, we make five classes which are water bodies, built-up, barren land, and Agriculture, mix vegetation.

\subsection{Accuracy Assessment}

Accuracy assessment is an important tool for image classification and comparison of classified images with real data. We calculate accuracy assessment thorough Kappa coefficient calculation and we calculate overall accuracy.

\section{Results and Discussion}

For LULC change detection after pre-processing, supervised classification was performed. The built-up area was the main focus of the research. This shows remarkable temporal changes during different time periods. Images were classified into Agriculture, Built-up area, Barren, water And Mix vegetation classes.

\subsection{Land Use and Land Cover in 1999}

The results of supervised classification for the land use land cover of Gujranwala in 1999 are presented in Figure 2. According to the results, the maximum area is covered by agricultural land. The built-up land is on the second number. In terms of percentage, $77 \%$ area is under Agriculture, while, 9.96\% under built-up land.

\subsection{Land Use and Land Cover of Gujranwala City in 2004}

For monitoring the land use and land cover of 2004 we use Land sat 8 ETM image and after doing supervised classification the land use and land cover of Gujranwala in 2004. During the last five years, from 1999 to 2004, agricultural land decreased due to an increase in a built-up area and different activities. But only a few changes in water bodies were monitored.

The image of 2004 was also classified into 5major classes through supervised classification, as shown in Figure 3. As compared to the results of the 1999 image, for the purpose of housing colonies agriculture land decreased and the built-up area has increased. Only in five years' time periods, it can be noticed that the Built-up area has increased. Due to the loss of the agricultural land and the proportion of Mix vegetation and barren land had increased. Due to the establishment of new housing

Table 1. Temporal changes from 1999-2019

\begin{tabular}{|l|l|l|l|l|l|l|}
\hline \multirow{2}{*}{ LULC classes } & $\mathbf{1 9 9 9}$ & $\mathbf{2 0 1 9}$ & Area changed & $\mathbf{1 9 9 9}$ & $\mathbf{2 0 1 9}$ & Area change \\
\cline { 2 - 8 } & Area $(\mathbf{s q . k m})$ & Area $(\mathbf{s q . k m )}$ & $\mathbf{s q . k m}$ & Area $(\%)$ & Area $(\%)$ & Percentage \\
\hline Water & 6.42 & 4.63 & -1.79 & 0.27 & 0.20 & -0.08 \\
\hline Built-up & 234.97 & 409.68 & 174.71 & 9.97 & 17.38 & 7.41 \\
\hline Barren & 70.99 & 138.98 & 67.99 & 3.01 & 5.90 & 2.88 \\
\hline Agriculture & 1833.16 & 1663.66 & -169.51 & 77.78 & 70.58 & -7.19 \\
\hline Mix vegetation & 211.45 & 140.05 & -71.40 & 8.97 & 5.94 & -3.03 \\
\hline
\end{tabular}

Source (Author 2019) 


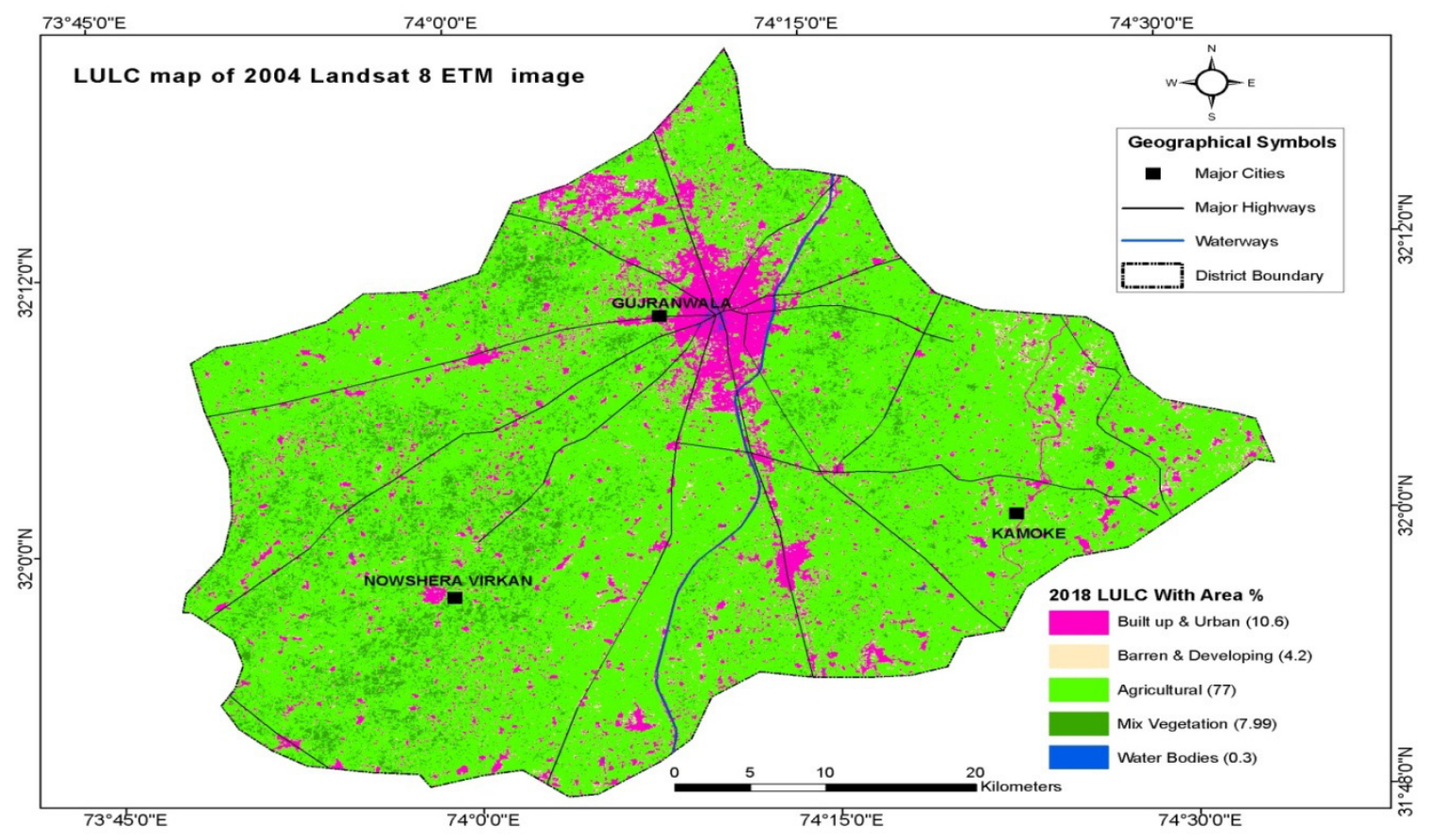

Figure 3. Land use land cover classification of 2004 satellite image.

colonies and the start of new commercial markets, agriculture land was changing into other land-use types.

\subsection{Land Use Land Cover in 2009}

According to Figure 4, Land sat 8 ETM image of 2009 was used for the supervised image classification. In 2009, again a decrease in agriculture land was monitored. But also, an increase in built-up land was monitored. There were also minor changes in water bodies. Due to the increase in built-up land, changes in barren land also occurred. Due to public awareness, there was an increase in Mix vegetation, mostly in an urban area.

As compared to the previous 5 years there is a minor change in water bodies but the built area increases 28 (Sq $\mathrm{km}$ ) which is more from the previous 5 years from 1999 to 2004 which was 16 (Sq km). Suddenly barren land decrease which was 43 (Sq km). There is decreased due to know about the importance of Agriculture land and get more food, profit through this land which is more beneficial for sufficient food quantity. Agriculture land decreases 130 (Sq km) which was more as compared to previous years. More important Mix vegetation increases highly which is $145(\mathrm{Sq} \mathrm{km})$. More increase in mix vegetation due to media awareness and education.

\subsection{Land Use and Land Cover in of Gujranwala City 2014}

According to Figure 5, Land sat 8 ETM image for the image classification represents the land use land cover on the map of Gujranwala city in 2014. During the five-year time period, we can see a decrease in agricultural land and an increase in built-up areas. There is also a decrease in water bodies and Mix vegetation.

In 2014 there was minor change in water bodies and barren land. The built-up area is showing a continuous increase. Again, decrease in Mix vegetation as compared to the 2004 time period. Almost $120 \mathrm{Sq} \mathrm{km}$ areas have decreased in Mix vegetation which is notable.

\subsection{Land Use and Land Cover in 2019}

Finally, according to the classified image of Lands at ETM 82019 the land use and land cover of Gujranwala in 2019 have also been altered. Again, agricultural land cover has decreased in 2019 and built-up land has been increasing rapidly to fulfill the constraint of the urban facilities for the people and built a different department to control the urban activities in the present time and future time.

According to Figure 6, Several changes have occurred in land cover and land use of Gujranwala city from 2014 to 


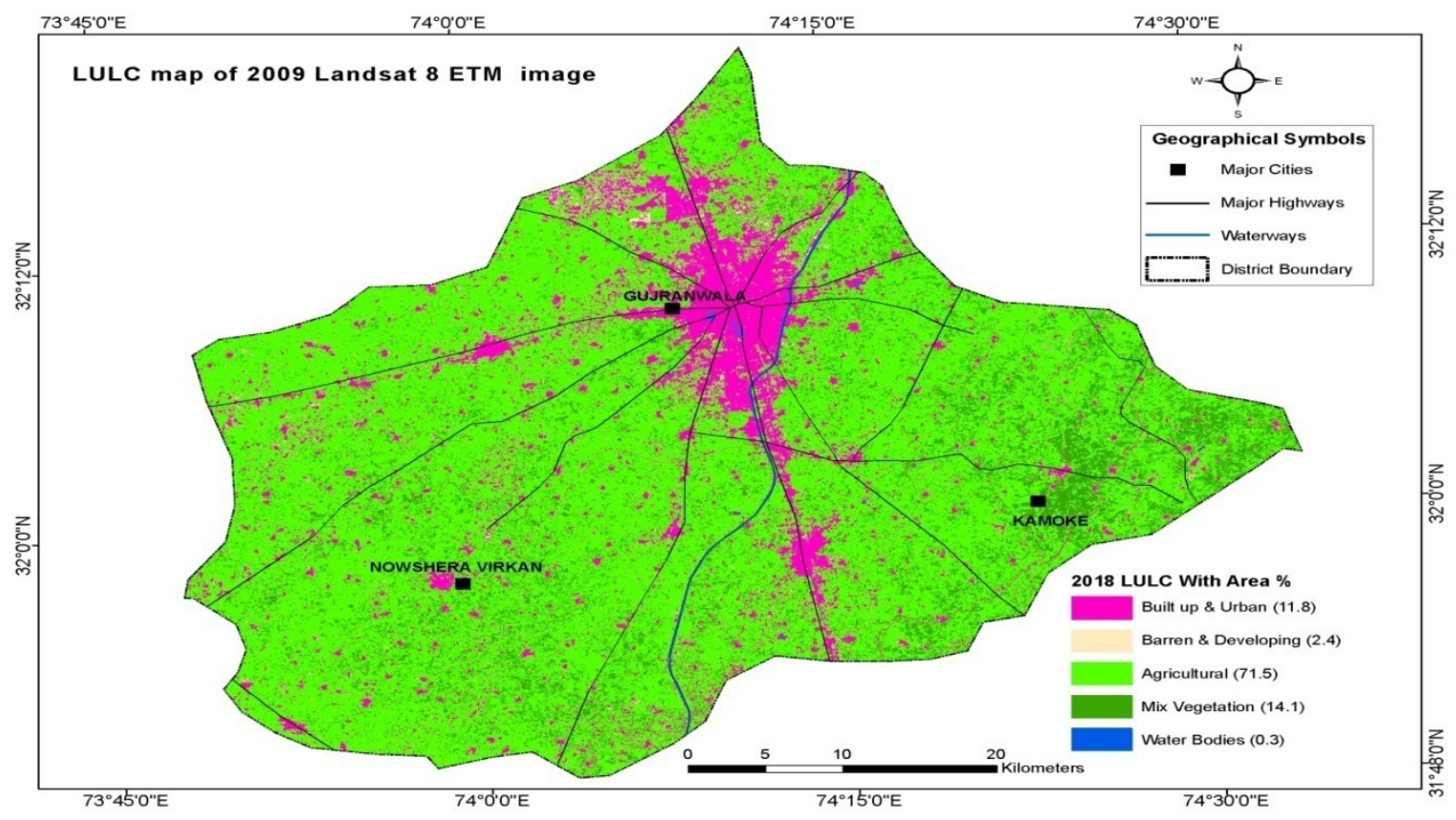

Figure 4. Classified image of land use and land cover in 2009.

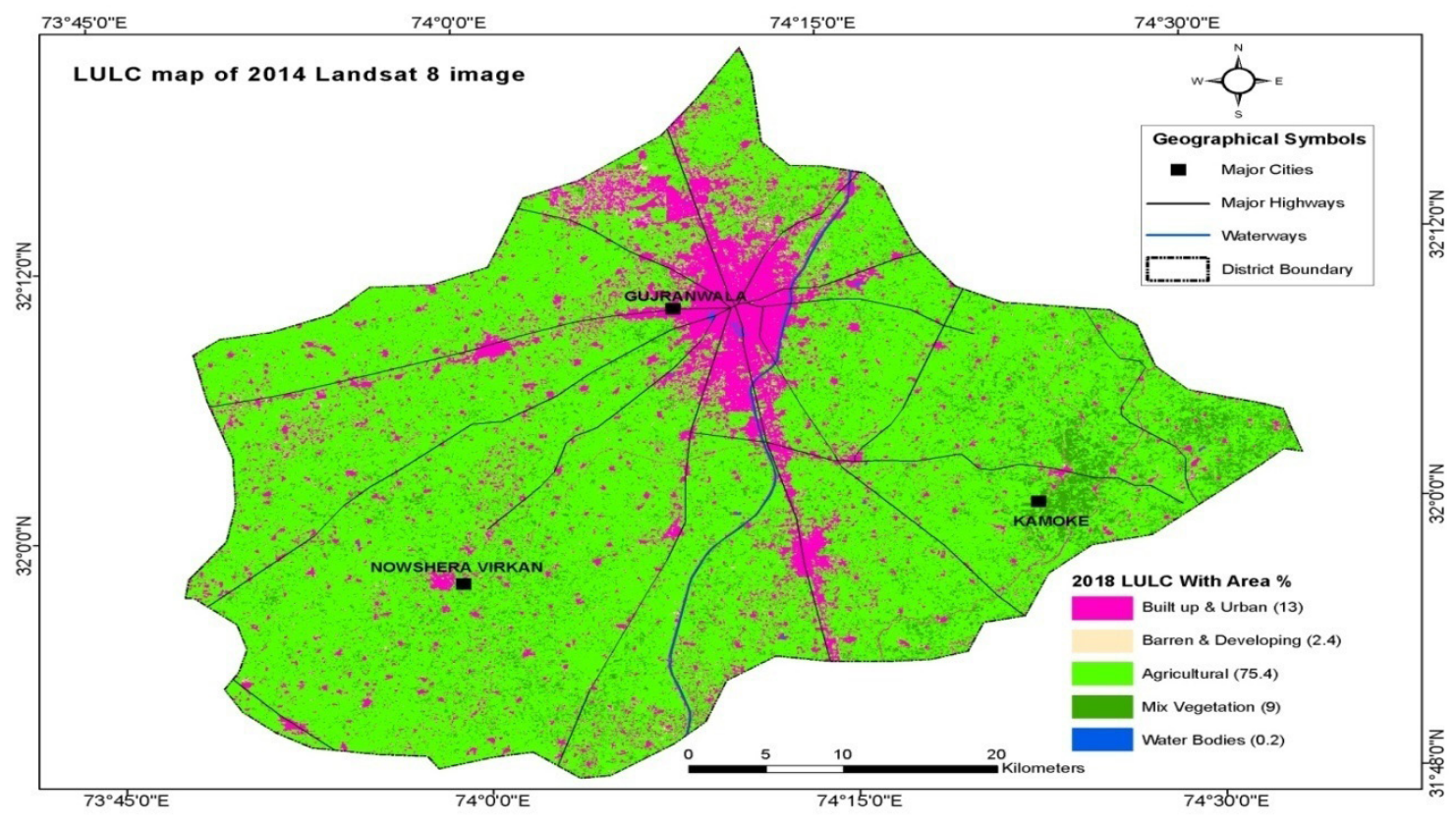

Figure 5. Classed image of land use and land cover in 2014.

2019, Due to the increase in built-up land, so the existing built-up land cover is 409.681 (sq km). The agricultural land can be transformed into a built-up area more rapidly due to population increase and demand for more land for residential and commercial purposes. For residential, commercial and markets purpose we need land to build buildings for their daily routine work. New housing colonies are required for better accommodation because people prefer to live a prosperous life. So, the agricultural land is rapidly transforming into a built-up area. In 2014 


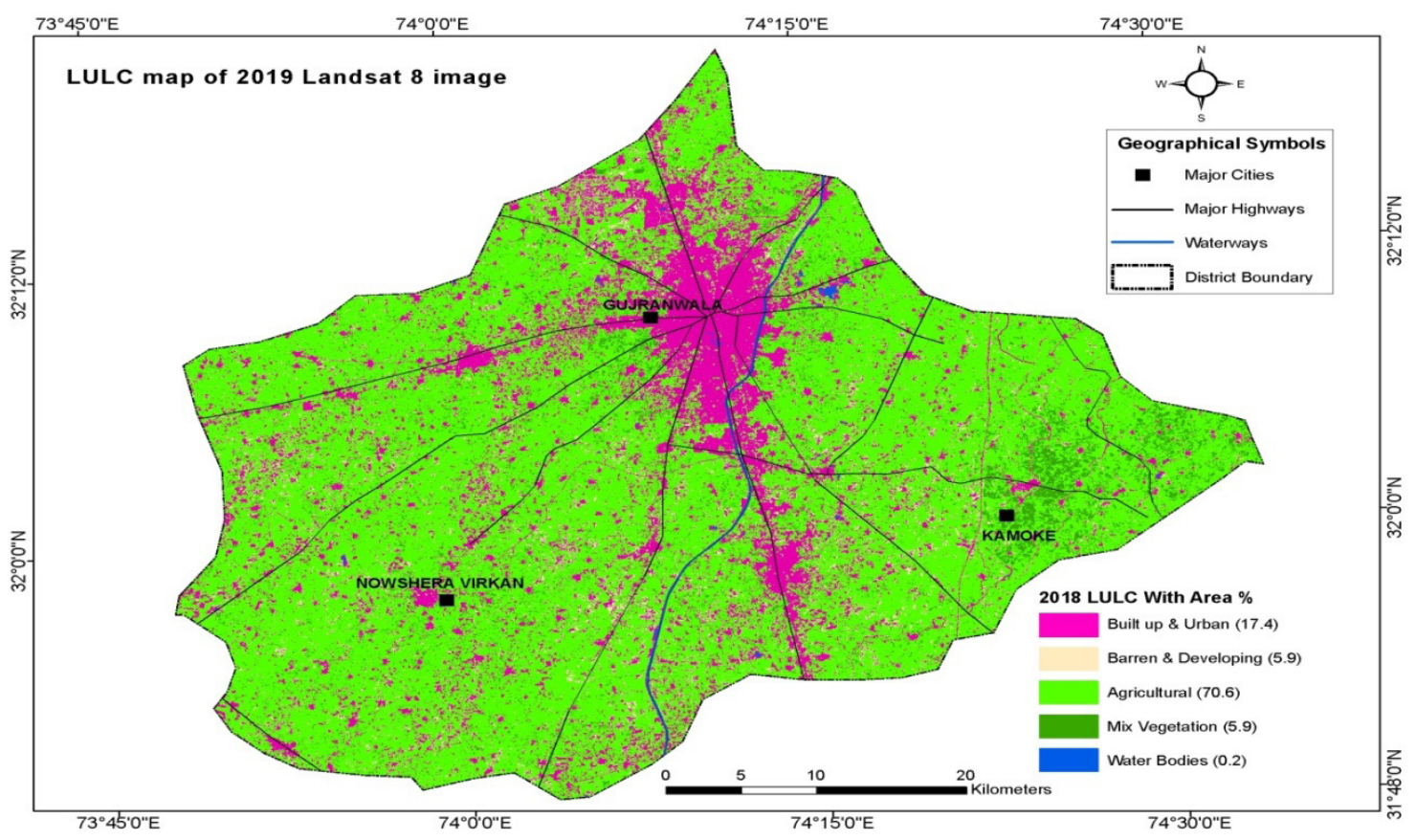

Figure 6. Image classification of land use and land cover in 2019.

the area under agricultural land cover was $1663.68 \mathrm{sq} \mathrm{km}$. The area under mix vegetation also decreased and it was $140.045 \mathrm{sq} \mathrm{km}$.

\subsection{Temporal Land Use Land Cover Changes in Gujranwala (1999-2019)}

Many changes occurred in the land use and land cover of Gujranwala city from 1999-2019. The maximum increase was recorded in the built area while the maximum decrease was recorded in agricultural land. The temporal change in LULC. During the last 20 years, only $1 \%$ area reduced underwater bodies cover due to different issues like excessive use of water. The built-up area has increased by $7.4 \%$ during the last 20 years. Barren land has also increased due to a decrease in water quantity and not upright use of fertile land. Barren land has increased by $2.9 \%$ in the two decades. Agricultural land has decreased by about $6.8 \%$ due to conversion into the built-up area and into barren land.

\subsubsection{Temporal Changes of Area in Five Classes of Land Use Land Cover From (1999- 2019)}

Table 1 shows the LULC time series analysis of five temporal images. After our research work we notice many time to time changes in Land use and Land cover classes during last 20 years. Highly affected land use land cover is the built-up land than other classes also changed during the previous time, sometimes there is an increase and sometimes there is a decrease in other classes. There is a noticeable decrease in the proportion of the land area of water, agriculture and mix vegetation from 1999 to 2019. But a Significant increase in Built-up and barren land can be seen. Water cover area has decreased from $6.42(\mathrm{sq} \mathrm{km})$ to 4.63 (sq km). So, the decrease is -1.79 (sq $\mathrm{km}$ ). The decrease in agriculture land and mix vegetation are -169.51 and -71.40 . The percentage of decrease for water, agriculture and mix vegetation is $-0.08 \%,-7.19 \%$ and $-3.03 \%$. Built-up and barren land increase due to the decrease in agriculture, mix vegetation and water bodies. The increase in built-up and barren land are 174.71 (sq $\mathrm{km}$ ) and 67.99 (sq $\mathrm{km})$. The percentage of increase in built-up and barren land is 7.41 and $2.88 \%$.

\subsection{Temporal Increase in Built-Up Area from 1999 to 2019}

In 20 years, there is a significant change in the proportion of the buildup area. With the help of overlay analysis, the true change has been monitored. Overlay analysis 


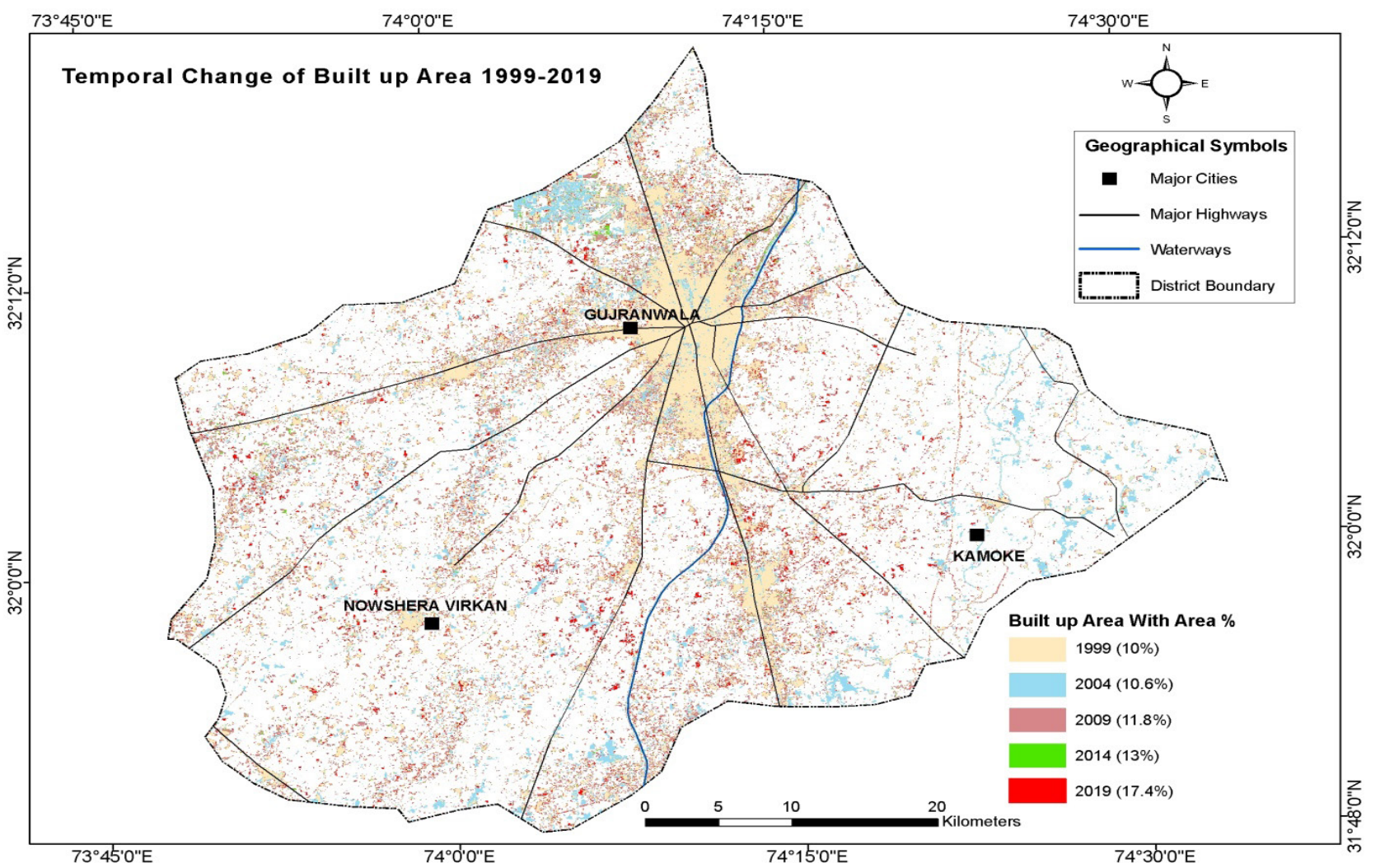

Figure 7. Temporal growth in the built-up area from 1999 to 2019. Source (Author 2019)

of all 5 classified images was performed. Only one class, the buildup area, was selected for monitoring timeseries change. The people prefer to live in a peaceful atmosphere and start to build new buildings in open land. So the conversion of agricultural Landis going on and we can see a noteworthy decrease in agriculture land. Figure 7 shows the temporal growth of the built-up area from 1999-2019.

In 1999 the proportion of the built-up area was only $10 \%$. Built-up areas continuously grow due to population growth and migration to urban areas because this, now Gujranwala is the $3^{\text {rd }}$ largest city of Punjab. In 2004 this percentage reaches to $10.6 \%$ but after 2004 due to rapid changes in a built-up area, most of the expansion occurred in the eastern parts of the Gujranwala city and new colonies were built for housing or living purpose. In 2009 the percentage of the built-up area increased up to $11.8 \%$ and maximum growth was on the northern side. In 2014 the maximum urban area increased by around 13\% in western and southern parts of the city. While in 2019 there was an increase of $17.4 \%$ in a built-up area.

\subsection{Land Use and Land Cover Changes from 1999-2019}

For showing the land use land cover changes we divided the land use map into five classes of water bodies: built-up land, barren land, agriculture and mix vegetation. We see many changes from 1999 to 2019. Mostly we see changes in built-up land. We want to see changes in land use and land cover on peri-urban areas.

We see different impacts on the social, economic and political life of the people which was live in peri-urban areas of Gujranwala city. It is a common fact when there is an increase in built-up land then we see a decrease in agriculture land. Many Government and private developers occupy hundreds of acres of agriculture land for housing schemes and built houses for living purposes on the peri-urban areas. So, in peri-urban areas, we see a decrease in agriculture land. In the last 20 years, this decrease is -169.51 (sq $\mathrm{km}$ ). Due to the decrease in agriculture land, we will face a shortage of food in future planning and pure drinking water. 
For a peaceful environment, people prefer to live in peri-urban areas because there is no pollution or traffic disturbance. Due to these housing schemes 174.71 (sq $\mathrm{km}$ ) built-up land increased in peri-urban areas. There are many causes of increasing built-up land in peri-urban areas. From which some are peaceful environment and pure drinking water and pollution-free air. When there is an increase in built-up land in peri-urban areas then we see a decrease in agriculture land.

Due to high land prices in urban areas, people prefer to migrate to peri-urban areas and try to live in a peaceful environment. So high land price is one of the major causes of migration from urban to peri-urban areas. When private and government policymakers cover agriculture land for housing societies then the price of land starts to increase in peri-urban areas. Due to migration in periurban areas, we see high land values in peri-urban areas after shifting of people from urban areas.

Due to an increase in peri-urban areas we see many changes in infrastructure like roads, pavement, sewerage systems, parks, schools, hospitals, different departments for other purposes so we see many changes in peri-urban infrastructure.

\section{Conclusion}

Spatial and temporal change is a reflection of human activities because these activities disturb the land use and land cover changes.

In the last 20 years and mostly built-up land increased in the previous 20 years in the north-south direction. Our results reveal that when we see an increase in built-up land then we see a decrease in agriculture land. The built-up land increased $174.71 \mathrm{sq} \mathrm{km}$ while agricultural land decreased 169.51 (sq km) in the last 20 years.

Water bodies' decreases during the last 20 years $0.1 \%$ and agriculture decrease $7.2 \%$ which is more decrease other than class and also mix vegetation decrease $4.1 \%$ but in the last 20 years we see an increase and decrease in mix vegetation.

An increase in a barren land and built-up land was recorded but the maximum increase was found in the proportion of built-up land which is $7.4 \%$ but from 2014 to 2019 there is more increase in other than years. Through the accuracy assessment process, we compare the real image with the reference image and obtain different errors like commission and omission errors and achieve accuracy like overall accuracy, producer accuracy, user accuracy. These are the 5 accuracy metrics. Accuracy assessment and overall accuracy is more for 2019 Land sat 8 ETM satellite classified image other than images. Almost producer accuracy and user accuracy are the same for all the land sat satellite classified images.

Land use and land cover changes generate many problems in urban and peri-urban area which has harmful effects on human beings, so we should control these changes. Through decreases in agriculture land, we have to face a shortage of food in upcoming years.

\section{References}

1. Alqurashi AF, Kumar L, Sinha P. Urban land cover change modelling using time-series satellite images: a case study of urban growth in five cities of Saudi Arabia. Remote Sens. 2016;8(10):838.

2. Sharma R, Chakraborty A, Joshi PK. Geospatial quantification and analysis of environmental changes in urbanizing city of Kolkata (India). Environ Monitor Assess. 2015;187:4206.

3. Rahman M. Detection of land use/land covers changes and urban sprawl in Al-Khobar, Saudi Arabia: an analysis of multi-temporal remote sensing data. ISPRS Int J GeoInform. 2016;5(2):15.

4. Gumma MK, Mohammad I, Nedumaran S, Whitbread A, Lagerkvist CJ. Urban sprawl and adverse impacts on agricultural land: a case study on Hyderabad, India. Remote Sens. 2017, 9, pp. 1136.

5. Analysis of urban growth and sprawl from remote sensing data. [cited 2010]. https://www.springer.com/gp/ book/9783642052989.

6. Gbanie SP, Griffin AL, Thornton A. Impacts on the urban environment: land cover change trajectories and landscape fragmentation in post-war Western Area, Sierra Leone. Remote Sens. 2018;10(1):129.

7. Rimal B, Zhang L, Keshtkar H, Haack BN, Rijal S, Zhang P. Land use/land cover dynamics and modeling of urban land expansion by the integration of cellular automata and Markov chain. IISPRS Int J Geo-Inform. 2018;7(4):154.

8. Hegazy IR, Kaloop MR. Monitoring urban growth and land use change detection with GIS and remote sensing techniques in Daqahlia governorate Egypt. Int J Sustain Built Environ. 2015;4(1):117-24.

9. Pellikka P, Alshaikh AY. Remote sensing of the decrease of juniper woodlands in the mountains of southwestern Saudi Arabia-reasons and consequences. Arab J Geosci. 2016;9:1-12. 
10. Uchegbulam O, Ayolabi EA. Satellite image analysis using remote sensing data in parts of Western Niger Delta, Nigeria. J Emerg Trends Eng Appl Sci. 2013;4(4):612-7.

11. Cai G, Ren H, Yang L, Zhang N, Du M, Wu C. Detailed urban land use land cover classification at the metropolitan scale using a three-layer classification scheme. Sensors. 2019;19(14):3120.
12. Akbar TA, Hassan QK, Ishaq S, Batool M, Butt HJ, Jabbar $\mathrm{H}$. Investigative spatial distribution and modelling of existing and future urban land changes and its impact on urbanization and economy. Remote Sens. 2019;11(2):1-15. 